\title{
Interleukin-1 Beta (IL-1/) in the Peripheral Blood of Dogs as a Possible Marker for the Detection of Early Stages of Inflammation
}

\author{
Christian Prachar ${ }^{1}$, Franz-Josef Kaup ${ }^{2}$, Stephan Neumann ${ }^{{ }^{*}}$ \\ ${ }^{1}$ Small Animal Clinic, Institute of Veterinary Medicine, University of Goettingen, Goettingen, Germany \\ ${ }^{2}$ German Primate Centre, Goettingen, Germany \\ Email: *sneuman@gwdg.de
}

Received August 24, 2013; revised September 24, 2013; accepted September 30, 2013

Copyright (C) 2013 Christian Prachar et al. This is an open access article distributed under the Creative Commons Attribution License, which permits unrestricted use, distribution, and reproduction in any medium, provided the original work is properly cited.

\begin{abstract}
Background: Cytokines are mediators of disease. Expression levels in the blood could be of clinical relevance. Objective: Aim of this study was to show if serum levels of IL- $1 \beta$ could be of any clinical relevance concerning dogs. IL- $1 \beta$ was measured in serum samples of healthy dogs to find a reference range for healthy individuals. Measurements of IL- $1 \beta$ should show if this substance was a possible marker for early stages of inflammation. Therefore, a possible relation between serum levels and grades of leukocytosis was analyzed. Methods: IL-1 $\beta$ concentrations in the blood were assessed by the use of a human enzyme linked immunosorbent assay (ELISA). 39 dogs with different inflammatory diseases were analyzed to figure out if there was a correlation between IL-1 $\beta$ serum levels and the number of leukocytes in peripheral blood. The control group consisted of 16 healthy dogs. Results: about half of the samples IL- $1 \beta$ were detected. Most of the patients showed no detectable amounts of IL- $1 \beta$. The IL-1 $\beta$ levels measured in the serum were stable for at least nine weeks when stored at $-20^{\circ} \mathrm{C}$. The patients tested positively on IL- $1 \beta$ had mostly lower-grade leukocytosis compared to those who had no IL- $\beta$ in serum. All the dogs which were suffering from disease but still had no traceable IL- $1 \beta$, showed a leukocytosis as a common symptom. Conclusion: This study showed that IL- $1 \beta$ could become an interesting marker for the detection of early stages of inflammation when leukocytosis does not yet appear in peripheral blood. Nonetheless, the possible use in diagnosis is restricted. This is due to the fact that there are only low amounts of IL- $1 \beta$ to be detected in the serum, even concerning patients are suffering from disease.
\end{abstract}

Keywords: IL-1 $\beta$; Interleukin-1 Beta; ELISA; Dog

\section{Introduction}

Besides TNF- $\alpha$ and IFN- $\gamma$, Interleukin-1 plays a central role in acute and chronic inflammation, both locally and systemically. There are two subtypes which are IL- $1 \alpha$ and IL-1 $\beta$. Both subtypes are mainly produced by monocytes, macrophages, endothelial cells and fibroblasts [1]. Although the two subtypes only share a sequence homology of $25 \%$ [2], they bind to the same receptor on T-cell-surface [3].

Both subtypes consist of precursor molecules with a molecular size of $31 \mathrm{kDa}$, which are split by converting enzymes. The mature IL- $1 \beta$-molecule has a size of 17 $\mathrm{kDa}$ and consists of the mature IL- $1 \beta$ molecule and a pro-segment. The cell releases a combination of these

${ }^{*}$ Corresponding author. molecules along with a prepro-IL-1 $\beta[1]$.

IL-1 acts as a pyretic in the body. This stimulates lymphocyte activity and the production of acute phase proteins in the liver as well as the release of collagenases and prostaglandins [4]. As IL-12, IL-1 induces IFN- $\gamma$-secretion by natural killer cells, which results in an IFN- $\gamma$-induced activation of macrophages. IL- $1 \alpha$ is only produced by monocytes and macrophages and is involved in different immunological processes, especially maintaining the dermal immunological barrier. IL- $1 \beta$ is also produced by astrocytes, oligodendroglia, adrenal cortical cells, platelets, osteoblasts and different kinds of T-cells. Because IL-1 $\beta$ is a hormone-like substance, it is like many other cytokines not stored in cells and tissue. This makes it difficult to detect IL- $1 \beta$ in cell culture supernatants, but it leads to acceptable results measuring 
IL-1 $\beta$-levels in blood serum samples [5].

Many different kinds of cells have receptors to bind IL-1 $\beta$. There are two different types of receptors for IL-1: The IL-1-receptor I (IL-1 RI) and the IL-1-receptor II (IL-1 RII). In addition to these, there also exists a nonbinding receptor accessory protein (IL-1 RAcP). Signaling is only mediated by IL-1 RI together with IL-1 RAcP, which interacts only with IL-1 RI in complex formation with IL-1 [1].

IL- $1 \beta$ is one of the most important inflammatory cytokines. IL- $1 \beta$ precipitates acute attacks of both local and systemic inflammation. It also contributes to several chronic diseases. Furthermore it is also known for mediating the acute phase response to infection, injury and immune challenge [6]. For example IL- $1 \beta$ induces the production of IL-6, but IL-6 inhibits the expression of the other pro-inflammatory cytokine. Besides TNF- $\alpha$, IL- $1 \beta$ is one of the first pro-inflammatory cytokines increasing in inflammation, which is important because every cytokine plays a precise role in regulating the expression of other cytokines [7].

In early stages acute inflammation is mediated by granulocytes, while chronic inflammation is mediated by mononuclear cells such as monocytes and lymphocytes. Neutrophil granulocytes are those of the first-responders of inflammatory cells and they migrate towards the site of inflammation. Within the first 6 to 12 hours of inflammatory reaction, the number of leukocytes increases and mature so-called segmented neutrophil granulocytes are set free by the bone marrow. In case of injury, neutrophils emigrate from blood vessels into the damaged tissue within a few minutes. Bacterial infections, tumors and many other different diseases can lead to inflammation too.

Over the past years many veterinary medical studies were made in order to analyze the expression of IL-1 $\beta$ in different tissues of the canine body [8-10]. Still only a few measurements were implemented on blood plasma or serum samples [11]. So far, no studies were made regarding a correlation between IL- $1 \beta$ serum levels in dogs suffering from different diseases.

The cause for this observation was to find out if IL- $1 \beta$ can be detected in serum of dogs and so it may become a useful diagnostic marker in veterinary medicine. As mentioned above, IL-1 $\beta$ acts as one of the early pro-inflammatory cytokines. It was interesting to see if there was a connection between increased levels of IL- $1 \beta$ and different ones which meanwhile established inflammatory markers like the number of leukocytes and neutrophil granulocytes.

\section{Material and Methods}

\subsection{Animals}

Altogether serum levels of 39 dogs were measured. 15 individuals were crossbreed while 24 were breed dogs. Most frequent breeds were German shepherd 3), Boxer 2), Rhodesian Ridgeback 2), Golden Retriever 2) and Beagle 2). The control group consisted of 16 healthy individuals. The study was made according to the German Animal Welfare Act.

Serum was isolated and aliquoted four times. The first time point was set to the time right after the isolation. The remaining three aliquots were frozen down immediately at $\leq-20^{\circ} \mathrm{C}$. After 3,6 and 9 weeks concentrations of IL- $1 \beta$ were measured.

The number of leukoctyes was measured by volume impedance with the Abbott Cell-Dyn ${ }^{\circledR} 3700$ Haematology Analyzer (Abbott GmbH \& Co KG, Wiesbaden/Germany).

\subsection{ELISA}

We used an ELISA developed for the quantitative determination of human IL-1 $\beta$ concentrations in serum (Quantikine ${ }^{\circledR}$ ELISA, catalog number DLB50, R \& D Systems, Minnesota/USA). The genetic sequence homology of $76.4 \%$ in both human and canine IL-1 $\beta[12]$ made it possible to use a human ELISA to measure serum levels of $\mathrm{IL}-1 \beta$ in canine blood samples.

The measurement ofIL- $1 \beta$ went according to manufacturer's recommendation. To determine the optical density of each well, a microplate reader set to $450 \mathrm{~nm}$ wave length was used.

The dogs tested for serum levels of IL- $1 \beta$ were patients of the Small Animal Clinic of Georg-August-University in Goettingen/Germany. Depending on theirtype of disease, diagnosis was confirmed by general examination, blood and urine tests, X-ray, ultrasound diagnostics, computed tomography, endoscopy, diagnostic laparoscopy and histopathological tests. In this study, the most severe diagnoses were mentioned. These were confirmed for a few patients who suffered from different diseases simultaneously.

Altogether, serum levels of 39 dogs with different diseases were measured. The control group consisted of 16 healthy individuals. The study was made according to the German Animal Welfare Act.

Statistical analysis was made with SPSS software. Due to the fact that both concentrations of IL- $\beta$ and the number of leukocytes were not normally distributed (Kolmogorov-Smirnov-test $p<0.001$ ), non-parametric methods were used for statistical analysis.

Blood samples from the dogs were taken to assess the stability of IL- $1 \beta$ when stored at $\leq-20^{\circ} \mathrm{C}$ Celsius. Serum was isolated and aliquoted into four samples. The first time point was set to the time right after the isolation. The remaining three aliquots were frozen down immediately at $\leq-20^{\circ} \mathrm{C}$. 
Measurements of IL- $1 \beta$ took place at the day of the blood taking and after 3, 6 and 9 weeks.

\subsection{Results}

\subsubsection{Storage}

Our analysis showed that IL- $1 \beta$ in serum can be stored at $\leq-20^{\circ} \mathrm{C}$ Celsius for at least nine weeks. Even beyond that time there was no obvious decrease of IL- $1 \beta$ found in the samples.

\subsubsection{IL-1 $\beta$ in Healthy Dogs}

Significantly higher serum levels of IL- $1 \beta$ were detected in patients suffering from disease compared to those of healthy controls (chi-square test $=0.003$ ) (Figure 1). In the healthy control group only two out of 16 dogs were tested positively on IL- $1 \beta$. Yet, they were both in very low concentrations $(0.11$ and $1.04 \mathrm{pg} / \mathrm{ml}) .14 \mathrm{dogs}$ $(87.5 \%)$ showed no detectable amount of IL- $1 \beta$ in their serum.

\subsubsection{IL-1 $\beta$ in Dogs with Different Internal Diseases}

Even though most of the serum levels werevery low, many of the patients showed positive results (22 out of 39 dogs). IL- $1 \beta$ serum concentrations were measured in 39 dogs with different internal diseases (Table 1), including non-neoplastic diseases, benign tumors and malignant neoplasia. 24 of the 39 dogs were bitches, while 15 were male dogs. 7 out of the 15 male dogs showed no detectable IL- $1 \beta$ in serum (46.6\%), and so did 12 of the 24 bitches $(50 \%)$. The age of the dogs with detectable IL- $1 \beta$ in their serum lay between 3.5 and 14.5 years (median 9.2, mean 10.0).

The highest level of IL- $1 \beta$ was detected in the serum of a dog with an adenoma of the hepatoid glands (64.71 $\mathrm{pg} / \mathrm{ml})$. This amount was significantly higher than those

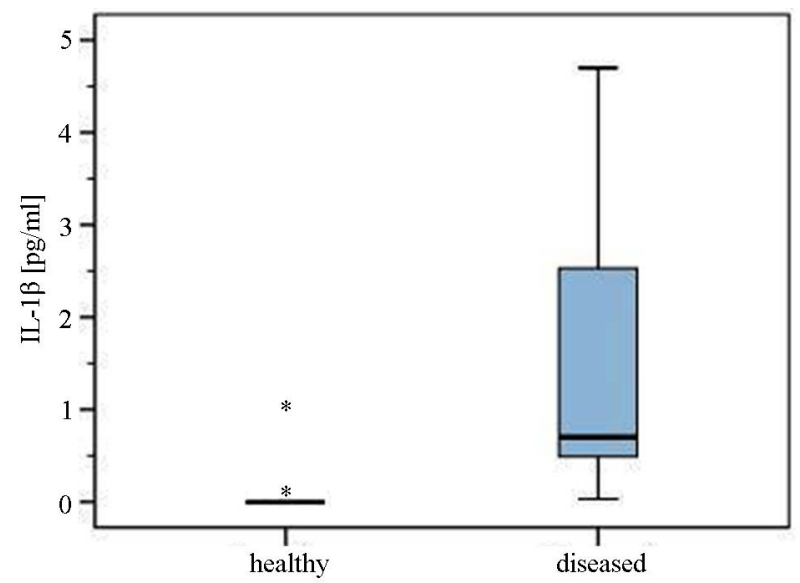

Figure 1. IL-1 $\beta$ in the serum of dogs with different diseases compared to healthy controls. Significantly higher serum levels were found in the group of dogs with different diseases compared to the healthy control group. of all the other dogs with detectable amounts of IL- $1 \beta$ (Figure 2).

\subsubsection{IL-1 $\beta$ Serum Levels and Leukocytosis}

A number of leukocytes $>12.000 \mathrm{~K} / \mu 1$ was stated leukocytosis. There was no connection found between IL- $1 \beta$ serum levels and leukocytosis (Figure 3). Noticeable is the fact that all dogs with no detectable amount of IL- $1 \beta$ in peripheral blood showed a leukocytosis (17 out of 17 , Table 2). 14 of the dogs with leukocytosis showed increased levels of neutrophil granulocytes.

Two of the healthy individuals had very low serum levels of 0.11 and $1.04 \mathrm{pg} / \mathrm{ml}$ withoutshowing the indication of a leukocytosis.

\section{Discussion}

In human medicine, many studies were conducted to prove the importance of IL- $1 \beta$ in inflammatory reactions of the body. Yet, in many cases they appear only for a short period of time in acute diseases as well as in chronic diseases with acute exacerbations. In one study an experimentally induced endotoxin shock in dogs based on the intravenous application of purified lipopolysaccharides from Escherichia coli led to increased IL-1-activity within the first 30 to 60 minutes with its peak after 90 minutes. During 6 to 24 hours after application, IL-1 was hardly detectable in blood [13]. Even in severe systemic inflammatory diseases, levels of free IL- $1 \beta$ are often undetectable, especially in peripheral blood.

Within the last few years, most of the studies were based on analyzing increased expression of IL- $1 \beta$ receptors in different body tissue. This was performed especially by histopathological analyzes of tissues which were affected by inflammatory reactions, as mentioned above.

Measurement of IL- $1 \beta$ in serum or plasma in medical diagnosis isapplied in human medicine. The reference range forIL- $1 \beta$ concerninghumans is stated with $<5$ $\mathrm{pg} / \mathrm{ml}$.

Some diseases go along with increased serum levels of IL- $1 \beta$. In healthy patients, the detectable amounts of IL- $1 \beta$ are ranging around the bottom line. However, some studies led to different results. A study regarding serum levels of different cytokines in patients with primary biliary cirrhosis, in which serum levels of IL- $1 \beta$ were ranged from 170 to $540 \mathrm{pg} / \mathrm{ml}$ in the healthy control group serves as an example [14].A correlation was found between IL- $1 \beta$ in serum and the severity of diseases likeLeishmaniasis [15] or SLE, especially with a Lupus nephritis [16]. Furthermore there was an increased IL-1 $\beta$ activity found in patients with sepsis [17], traumatic neuronal injury [18] and arteriosclerosis [19]. One study showed that IL- $1 \beta$ also is involved in the aging process 
Table 1. List of diseases of dogs tested positively on IL-1 $\beta$.

\begin{tabular}{|c|c|c|}
\hline & Diagnosis & $\mathrm{IL}-1 \beta[\mathrm{pg} / \mathrm{ml}]$ \\
\hline 1) & Adenoma of the hepatoid glands & 64.71 \\
\hline 2) & Haemangiosarcoma of the spleen & 4.7 \\
\hline 3) & Chronic renal failure, anaemia & 4.7 \\
\hline 4) & Malignant mesenchymal dermal tumor & 3.56 \\
\hline 5) & Cystic carcinoma of the mamma and tubular adenoma & 2.9 \\
\hline 6) & Haemangiosarcoma of the spleen & 2.53 \\
\hline 7) & Steatonecrosis with fibrosingsteatitis, pancreatitis & 2.5 \\
\hline 8) & Lipoma & 1.75 \\
\hline 9) & Borreliosis, anaplasmosis, high anti-thrombocyte antibody titer & 1.33 \\
\hline 10) & Prostate carcinoma & 0.82 \\
\hline 11) & Renal adenocarcinoma & 0.75 \\
\hline 12) & Pyelonephritis, haemangiosarcoma of the spleen & 0.65 \\
\hline 13) & Haemorrhagic liver necrosis & 0.61 \\
\hline 14) & Retrobulbar round cell tumor (malignant lymphoma) & 0.6 \\
\hline 15) & Oral malignant melanoma & 0.53 \\
\hline 16) & Cystic granulosa cell tumor, leiomyoma of the cervix & 0.51 \\
\hline 17) & Cystitis caused by struvituroliths & 0.49 \\
\hline 18) & Gingivitis and stomatitis & 0.29 \\
\hline 19) & Chronic renal failure & 0.25 \\
\hline 20) & Solid to papillary carcinoma of the mamma & 0.18 \\
\hline 21) & Pyometra & 0.06 \\
\hline 22) & Purulent mastitis & 0.03 \\
\hline
\end{tabular}

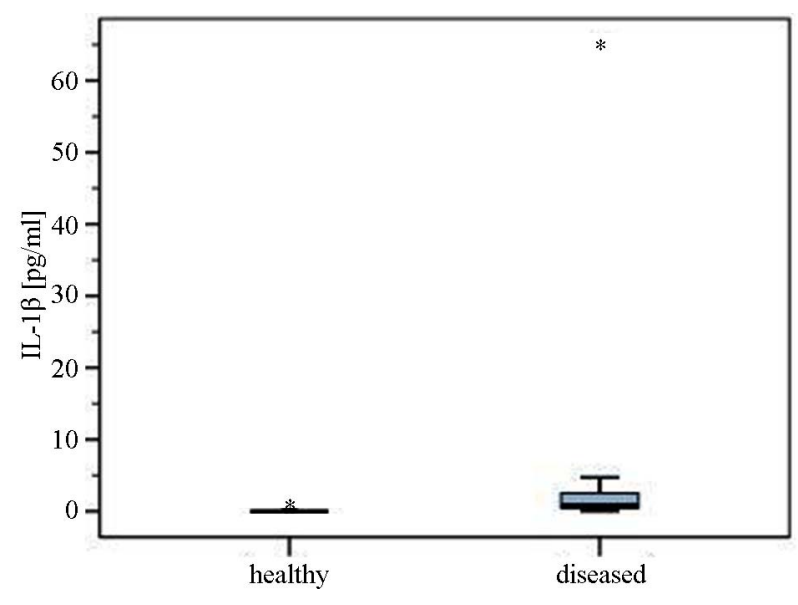

Figure 2. IL-1 $\beta$ in the serum of dogs with different diseases compared to healthy controls with statistical outlier in the group of dogs with disease: $64.71 \mathrm{pg} / \mathrm{ml}$. As you can see this dog in the diseased group showed a serum level which was noticeably higher than those of all other dogs.

[20].

In human medicine, the blocking effect of IL- $1 \beta$ is meanwhile used therapeutically. An example for this is the treatment of rheumatoid arthritis and chronic obstruc-

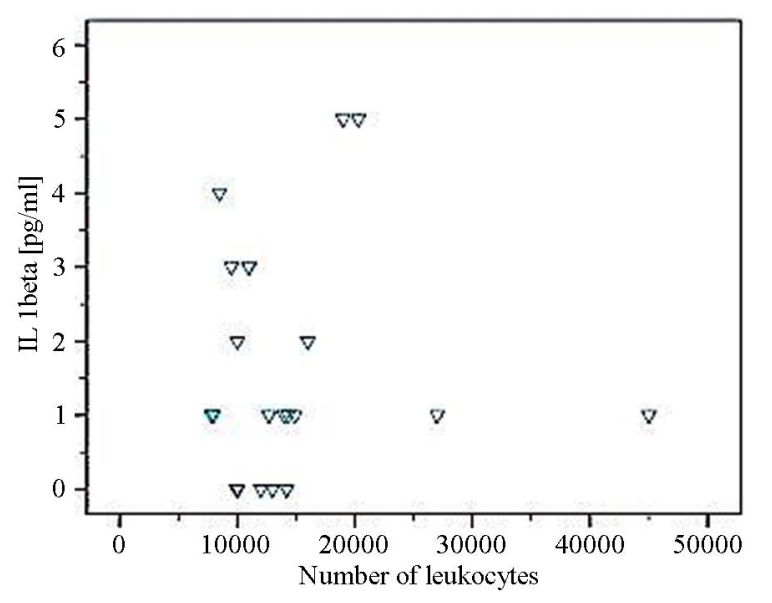

Figure 3. Numbers of leukocytes in dogs with detectable serum levels of IL-1 $\beta$. It is noticeable, that all the dogs without free IL-1 $\beta(n=17)$ showed a leukocytosis, while most of the dogs with measurable IL-1 $\beta$ had a normal leukocyte count (see above in Table 2).

tive pulmonary disease. The most important agent is Canakinumab which is a human monoclonal antibody against IL- $1 \beta$ and was developed by Novartis [21]. So far no comparable studies on IL- $1 \beta$ in dogs were 
Table 2. Comparison of IL-1 $\beta$ serum levels of dogs with and without a leukocytosis (number of leukocytes $>12.000 \mathrm{~K} / \mu \mathrm{l})$.

\begin{tabular}{|c|c|c|c|c|c|}
\hline & & \multicolumn{4}{|c|}{ Number of leukocytes $>12.000 \mathrm{~K} / \mu 1$} \\
\hline & & & not found & found & total \\
\hline \multirow[t]{2}{*}{$\mathrm{IL}-1 \beta[\mathrm{pg} / \mathrm{ml}]$} & negative & Dogs & 0 & 17 & 17 \\
\hline & positive & Dogs & 10 & 12 & 22 \\
\hline Total & & Dogs & 10 & 29 & 39 \\
\hline
\end{tabular}

made. There are no copious studies for serum levels of IL-1 $\beta$ in healthy or ill dogs, especially not regarding the measurement of serum levels. Furthermore, blocking IL- $\beta$ has no relevance in treating acute or chronic inflammatory diseases in veterinary medicine.

Since there are no reliable reference ranges for serum levels of IL- $1 \beta$ concerning dogs, one aim of our study was to find out if IL- $1 \beta$ can be detected in the serum of healthy dogs. For the possible routinely use in veterinary medicine, it was furthermore relevant to find out if measurements of IL-1 $\beta$ serum levels are diagnostically conclusive. This is due to the fact that blood analyzes are less invasive and can lead to faster results than other tests.

\section{Conclusions}

Results of our study show that concerning healthy dogs, IL-1 $\beta$ mostly can't be detected at all or only in very low concentrations in ranges of $<1 \mathrm{pg} / \mathrm{ml}$.

Our study should show if IL-1 $\beta$ was a possible marker for inflammatory reactions concerning dogs which suffered from different internal diseases. The outcome of this study leads to the assumption that IL- $1 \beta$ in serum increases in the majority of cases in early stages of inflammation, respectively during acute exacerbations of disease. In progressed stages when leukocytosis appears in peripheral blood, the free IL- $1 \beta$ in serum decreases. We found evidence for this because all dogs without detectable IL-1 $\beta(\mathrm{n}=17)$ in blood serum showed a leukocytosis. Though in this study there was no statistical significance finding between IL- $1 \beta$ serum levels and the number of leukocytes, it is remarkable that all the patients with no detectable IL-1 $\beta$ in their serum showed a leukocytosis.

In healthy individuals there is hardly any IL- $1 \beta$ finding in peripheral blood. Most of the already implemented studies are mainly conducted in human medicine and show that healthy individuals have IL- $1 \beta$ serum concentrations below the minimum detectable dose. Furthermore, even patients suffering from inflammatory diseases seldom show IL- $1 \beta$ serum levels above the minimum detectable dose, as described above. In this study only two healthy dogs were tested positively on IL- $1 \beta$, but only in very low concentrations.

The dogs in this study suffered from many different diseases. Only two diseases appeared in more than one $\operatorname{dog}$ (haemangiosarcoma of the spleen, $\mathrm{n}=2$, and chronic renal failure, $\mathrm{n}=2$ ). Those diseases led to different concentrations of IL-1 $\beta$ (haemangiosarcoma 2.53 and 4.7 $\mathrm{pg} / \mathrm{ml}$, chronic renal failure 0.25 and $4.7 \mathrm{og} / \mathrm{ml}$ ) which are hardly comparable. Further studies on a larger group of dogs suffering from the same disease should follow.

The highest serum levels were found in dogs with very different diseases: the highest amount of IL- $1 \beta$ was found in a dog with benign tumor $(64.71 \mathrm{pg} / \mathrm{ml})$, followed by one with a malignant neoplasia $(4.7 \mathrm{pg} / \mathrm{ml})$ and one with chronic renal failure $(4.7 \mathrm{pg} / \mathrm{ml})$. It is noticeable that no other dogs in the diseased group $(n=39)$ reached a serum level near the highest one.

Even if IL- $1 \beta$ increases in different periods of progress of the disease, there seem to be no steadily high serum levels. Follow-up measurements during the progress of disease (whether treated or not) could indicate if different stages of disease are associated with the increase or decrease of IL- $1 \beta$ in serum. This may be caused by the fact that detectable amounts of IL- $1 \beta$ appear very early in inflammation. As soon as inflammation begins, the number of neutrophil granulocytes increases. Stored neutrophils are set free from the bone marrow and after that new neutrophils are produced.

Since IL- $1 \beta$ is a very important pro-inflammatory cytokine with many different functions regarding the beginning and the progression of inflammation, it could become an interesting diagnostic marker even in veterinary medicine.

We assume that increased IL- $1 \beta$ can be found mainly in a time when already no leukocytosis appears in blood. Followed by leukocytosis with mostly banded neutrophils, increasing IL-1 $\beta$ could be used as an indicator for the early pro-inflammatory immune response. Our study suggests that measurement of IL- $1 \beta$ in the serum of dogs suffering from disease could become a useful addition to the measurement of the leukocyte count, which is routinely used in veterinary medicine since decades. Another useful marker for inflammation is the C-reactive protein (CRP). Further studies should be conducted to find out if there is a direct relation between the number of leukocytes or serum levels of CRP and the detectable amount of IL- $1 \beta$ in peripheral blood. Furthermore it could be interesting to look at the neutrophil granulocytes in detail, because Seite: 2 new cells must be pro- 
duced when the stored and mature neutrophils are used up. This can be seen in blood analyzes when the amount of the so-called banded neutrophils increases compared to the mature and segmented neutrophils.

Detectable amounts of IL- $1 \beta$ are correlated with any inflammatory reaction. Still, there appears to be a very limited period of time in which free IL- $1 \beta$ can be detected in the serum. This unfortunate fact is the reason why IL- $1 \beta$ is not used in common diagnosis.

Diagnostic techniques with a higher sensitivity like the ones with lower concentration ranges may be more appropriate for measurements of IL- $1 \beta$ in the serum. Even if measurements with a human ELISA showed good results, a specific ELISA for canine IL- $1 \beta$ could lead to better results.

Further studies on a larger population could find evidence that IL- $1 \beta$ perhaps is a useful marker for early stages of inflammation, comparable to the fact that the grade of leukocytosis is a good parameter to assess the stage of inflammation.

\section{REFERENCES}

[1] C. A. Dinarello, "Biologic Basis for Interleukin-1 in Disease,” Blood, Vol. 87, No. 6, 1996, pp. 2095-2147.

[2] J. L. Telford, G. Macchia, A. Massone, V. Carinci, E. Palla and M. Melli, "The Murine Interleukin 1 Beta Gene: Structure and Evolution," Nucleic Acids Research, Vol. 14, No. 24, 1986, pp. 9955-9963. http://dx.doi.org/10.1093/nar/14.24.9955

[3] P. L. Kilian, K. L. Kaffka, A. S. Stern, D. Woehle, W. R. Benjamin, T. M. Dechiara, U. Gubler, J. J. Farrar, S. B. Mizel and P. T. Lomedico, "Interleukin 1 Alpha and Interleukin 1 Beta Bind to the Same Receptor on T Cells," The Journal of Immunology, Vol. 136, No. 12, 1986, pp. 4509-4514.

[4] C. A. Meyers, K. O. Johanson, L. M. Miles, P. J. McDevitt, P. L. Simon, R. L. Webb, M. J. Chen, B. P. Holskin, J. S. Lillquist and P. R. Young, "Purification and Characterization of Human Recombinant Interleukin-1 Beta," The Journal of Biological Chemistry, Vol. 262, No. 23, 1987, pp. 11176-11181.

[5] S. K. Durum, J. A. Schmidt and J. J. Oppenheim, "Interleukin 1: An Immunological Perspective," Annual Review of Immunology, Vol. 3, No. 1, 1985, pp. 263-287. http://dx.doi.org/10.1146/annurev.iy.03.040185.001403

[6] C. A. Dinarello, "Interleukin-1 and the Pathogenesis of the Acute-Phase Response," The New England Journal of Medicine, Vol. 311, No. 22, 1984, pp. 1413-1418. http://dx.doi.org/10.1056/NEJM198411293112205

[7] F. Ceciliani, A. Giordano and V. Spagnolo, "The Systemic Reaction during Inflammation: The Acute-Phase Proteins," Protein and Peptide Letters, Vol. 9, No. 3, 2002, pp. 211-223.

http://dx.doi.org/10.2174/0929866023408779

[8] A Grone, S. Fonfara and W. Baumgartner, "Cell TypeDependent Cytokine Expression after Canine Distemper
Virus Infectio," Viral Immunology, Vol. 15, No. 3, 2002, pp. 493-505.

http://dx.doi.org/10.1089/088282402760312368

[9] M. F. Rai, P. S. Rachakondaa, K. Manning, B. Vorwerk, L. Brunnberg, B. Kohn, M. F. G. Schmidt, "Quantification of Cytokines and Inflammatory Mediators in a ThreeDimensional Model of Inflammatory Arthritis," Cytokine, Vol. 42, No. 1, 2008, pp. 8-17. http://dx.doi.org/10.1016/i.cyto.2008.02.004

[10] J. Y. Yhee, C.-H. Yu, J.-H. Kim and J.-H. Sur1, "Effects of T Lymphocytes, Interleukin-1, and Interleukin-6 on Renal Fibrosis in Canine End-Stage Renal Disease," Journal of Veterinary Diagnostic Investigation, Vol. 20, No. 5, 2008, pp. 585-592. http://dx.doi.org/10.1177/104063870802000508

[11] K. K. Al'tsivanovich and V. N. Gurin, "Activity of Blood Interleukin-1 in Dogs during Work Hyperthermia," Bulletin of Experimental Biology and Medicine, Vol. 110, No. 12, 1990, pp. 565-567.

[12] J. T. Soller, H. Murua-Escobar, S. Willenbrock, M. Janssen, N. Eberle, J. Bullerdiek and I. Nolte, "Comparison of the Human and Canine Cytokines IL-1 (Alpha/Beta) and TNF-Alpha to Orthologous Other Mammalians," Journal of Heredity, Vol. 98, No. 5, 2007, pp. 485-490.

http://dx.doi.org/10.1093/jhered/esm025

[13] T. Miyamoto, T. Fujinaga, K. Yamashita and M. Hagio, "Changes of Serum Cytokine Activities and Other Parameters in Dogs with Experimentally Induced Endotoxic Shock," The Japanese Journal of Veterinary Research, Vol. 44, No. 2, 1996, pp. 107-118.

[14] V. Barak, C. Selmi, M. Schlesinger, M. Blank, N. Agmon-Levin, I. Kalickman, M. E. Gershwin and Y. Shoenfeld, "Serum Inflammatory Cytokines, Complement Components, and Soluble Interleukin 2 Receptor in Primary Biliary Cirrhosis," Journal of Autoimmunity, Vol. 33, No. 3-4, 2009, pp. 178-182. http://dx.doi.org/10.1016/j.jaut.2009.09.010

[15] E. A. Fernandez-Figueroa, et al., "Disease Severity in Patients Infected with Leishmania Mexicana Relates to IL-1 $\beta$," PLOS Neglected Tropical Diseases, Vol. 6, No. 5, 2012, p. E1533.

[16] B. Brugos, Z. Vincze, S. Sipka, G. Szegedi and M. Zeher, "Serum and Urinary Cytokine Levels of SLE Patients," Pharmazie, Vol. 67, No. 5, 2012, pp. 411-413.

[17] S. Papin, S. Cuenin1, L. Agostini1, F. Martinon1, S. Werner, H.-D. Beer, C. Grütter, M. Grütter and J. Tschopp, "The SPRY Domain of Pyrin, Mutated in Familial Mediterranean Fever Patients, Interacts with Inflammasome Components and Inhibits Proil-1 $\beta$ Processing," Cell Death and Differentiation, Vol. 14, No. 8, 2007, pp. 1457-1466. http://dx.doi.org/10.1038/sj.cdd.4402142

[18] S. M. Allan, P. J. Tyrrell and N. J. Rothwell, "Interleukin-1 and Neuronal Injury," Nature Reviews Immunology, Vol. 5, No. 8, 2005, pp. 629-640. http://dx.doi.org/10.1038/nri1664

[19] M. Kusuhara, K. Isoda and F. Ohsuzu, "Interleukin-1 and Occlusive Arterial Diseases," Cardiovascular \& Hematological Agents in Medicinal Chemistry, Vol. 4, No. 3, 
2006, pp. 229-235.

http://dx.doi.org/10.2174/187152506777698335

[20] K. S. Kornman, "Interleukin 1 Genetics, Inflammatory Mechanisms, and Nutrigenetic Opportunities to Modulate Diseases of Aging," The American Journal of Clinical Nutrition, Vol. 83, No. 2, 2006, pp. S475-S483.
[21] C. A. Dinarello, A. Simon and J. W. van der Meer, "Treating Inflammation by Blocking Interleukin-1 in a Broad Spectrum of Diseases," Nature Reviews Drug Discovery, Vol. 11, No. 8, 2012, pp. 633-652. http://dx.doi.org/10.1038/nrd3800 